\title{
Tax Illusion and Labour Supply of Married Women: Evidence from German Data
}

\author{
Heinz König, François Laisney, Michael Lechner and Winfried Pohlmeier*
}

\section{INTRODUCTION}

Existing tax systems imply complex budget constraints, so that the assumption that individuals act on the basis of complete knowledge of the tax system has to be regarded as a theoretical borderline. Yet it is difficult to model the extent of the perception of tax costs, because questioning how economic agents decide on their optimal information level leads the economist on unsteady ground. In this respect it is significant that Atkinson and Stiglitz (1980, pp. 322-323) address this perception problem only in connection with public goods, whereas it really applies to most of the situations they consider.

The specific issues examined in this study are (i) to what extent do consumers (here married women) perceive their true marginal tax rate when they make their labour supply decisions, and (ii) how does the perception of the marginal tax rate differ among various socio-economic groups? It is hardly necessary to dwell on the importance of this problem for investigators attempting to quantify the impact of fiscal policies on household behaviour. For instance, the idea to

\footnotetext{
* Prof. Dr., FB Volkswirtschaftslehre, Universität Mannheim, 68131 Mannheim, Germany. Prof. Dr., Université Louis Pasteur Strasbourg, BETA UA 1237 du CNRS 38 boulevard d'Anvers, 6707 Strasbourg Cedex, France. Dr., Lehrstuhl für Volkswirtschaftslehre Universität Mannheim, 68131 Mannheim, Germany. Prof. Dr., Fakultät für Wirtschaftswissenschaften und Statistik, Universität Konstanz, Postfach 5560 D 124, 78434 Konstanz, Germany. Financial support from the Deutsche Forschungsgemeinschaft (DFG) and from the SPES project 'Unemployment in Europe' is gratefully acknowledged. Former versions of this paper have been presented at workshops and conferences in Louvain-la-Neuve, Florence, Gmunden and Chelwood Gate. We would like to thank the participants for comments and discussions, with special thanks to Samuel Bentolila, Per-Anders Edin, Wolfgang Franz, Bertil Holmlund, Peter Kooreman, Gauthier Lanot and Steve Machin. Thanks also to Carla Fernandes-Schlegel, Katarina Katsuli and Daniela D'Agostino for able research assistance. The comments of an anonymous referee are gratefully acknowledged. Finally we would like to thank the DIW in Berlin for providing the data. The usual disclaimer applies.
} 
create economic incentives by reducing marginal taxes will only make sense to the extent that the tax reduction is perceived.

Investigating the individuals' perception of marginal taxes questions the paradigm of the rational utility-maximizing consumer. Empirical models of consumer behaviour following this paradigm incur the risk of mixing up normative and positive theory, in the sense that they are more likely to describe how the consumer should behave rather than how she does behave. Since the seminal work of Kahneman and Tversky (1979) we know that in certain well-defined situations consumers' choices under uncertainty are inconsistent with the assumption of rational acting. In these situations economic theory and econometrics will make systematic errors when predicting responses to tax changes.

In microeconometric models of labour supply it is usually assumed either that individuals have perfect knowledge about the implications of the tax system as to their marginal wage rates or that individuals only know their pre-tax wages (see, for instance the survey of Hausman, 1985). From a purely theoretical point of view the latter approach is of course far less satisfactory. On the other hand, it can happen that models which adopt the perfect knowledge assumption do less well in terms of goodness of fit and diagnostic checks (see, König et al. 1993, for evidence from French data).

However, it is possible to think of alternative specifications of labour supply which nest the perfect knowledge case and the case of complete ignorance. This is the starting point for our analysis. Firstly, a logarithmic specification for the wage allows a convenient additive decomposition into a gross wage term and a marginal tax rate term which can be given different coefficients (see Rosen 1976a and b, and the discussion in Nakamura and Nakamura 1981). Introducing interactions between the marginal tax rate and household characteristics is an easy way to allow for different behavioural patterns in this framework. Our empirical analysis will focus on this extension of the standard labour supply model.

For workers in most western economies, marginal wages are only incompletely known when they make their labour supply decision. Unexpected changes in taxable income due to new collective bargaining arrangements, illness, extra bonuses, job change and overtime work produce tax uncertainty so that the true marginal tax rate is only known a posteriori, in the year following the one where decisions supposedly based on that knowledge are made. Standard labour supply models under uncertainty are able to deal with this kind of uncertainty in a general manner by introducing the marginal wage rate as a stochastic price. However, by applying the usual rational expectations framework, little can be learned about which social groups have a better perception of the marginal tax rate. 
More specifically, it can be argued that the non-takeup of social benefits is an important example for an individual's misperception of the budget constraint. Again, as in the case of tax uncertainty, the non-takeup may be a result of rational behaviour. Moffitt (1983), for instance, develops a model of welfare stigma where benefits are valued less highly than privately earned income. Efforts in terms of applying and maintaining welfare benefits may also outweigh the potential rewards from receipt, leading to a disregard of the true budget constraint. In a similar vein, Pommerehne and Schneider (1978) study fiscal illusion in the tradition of public choice theory, on the basis of a cross-section of 110 Swiss cities. Their findings support the view that individuals reveal systematic misperceptions of the size of the tax burden and other public receipts borne by them, and of the benefits returned for public expenditures. Misperception does not only result from the complexity of the revenue system (including the timing of the public revenue burden) but is also significantly correlated with the type of democratic decision making practiced.

Our motive for investigating differences in the perception by various social groups thus lies in the following considerations. Some individuals may have no real incentive to go to bother gathering the information and knowledge necessary for the computation of their marginal tax rate, namely those who pay little tax anyway, and those who have higher costs for, than anticipated benefits from, gathering and processing information. This will in particular be the case for people who are relatively isolated. With these points in mind one may expect the poor, the unemployed, the less educated as well as the youngest and the oldest (the latter may also fail to adjust to changes in the tax system, even if they had a good approximation of it at some point in their life cycle) to care relatively less about their marginal tax rate than the rest. Indeed, the purely financial focus of the neoclassical labour supply model is challenged by the psychological literature (see Dilnot and Duncan, 1992, for a discussion), which seeks to extend the range of factors determining labour supply. Wahlund (1987) argues from a psychological point of view that the perception of a reduction in marginal taxes depends on various factors such as the context or background, past experience as well as attention factors such as motives, expectations, and payoffs. For instance, individuals who have faced large fluctuations in income as well as individuals experienced in the management of wealth, where taking taxes into consideration is very important, are likely to evaluate their true tax rate more accurately than others do. Following prospect-theoretical reasoning, he argues that an increase in the marginal tax rate should be perceived as bigger than a corresponding decrease later on, because the value function for losses is steeper than the value function for gains. Wahlund (1992) reports on empirical studies for Great Britain and Sweden which find that perceived marginal taxes 
are on average substantially lower than true tax rates, and that there exist large variations in the perceived tax rates among individuals.

Beyond this discussion, we would like to argue that some married women may even refuse to take their marginal wage rate into account, as being discouraging and unfairly high. This is likely to happen for relatively well-off women in the case of joint taxation with the same marginal tax rate on both earners. Individuals may also appear to disregard their marginal tax rate because they are prepared to work in periods where the usual simple static labour supply models would predict that it is not profitable for them to do so. Examples of such situations could be as follows: (i) better prospects later may make it attractive to work now, even if the immediate rewards seem comparatively small (trainees offer an example: their wage cannot explain their current labour supply; women re-entering the labour market after a non-participation spell for raising children are another example: for psychological reasons, they may have almost zero current reservation wage, yet this may increase rapidly when they regain confidence); (ii) work may enter utility positively (because of social contacts, prestige, self-esteem, independence, etc.). Admittedly, the standard labour supply models are not able to handle these aspects, but a direction of the effects mentioned could be that women with older children will be less inclined to take account of their marginal tax rates than women with younger children or without children.

At any rate it seems interesting to try to see what data may have to say on these points, even though the interpretation of results calls for extreme caution. In the application we shall use panel data for Germany. At this stage it is perhaps worth stressing that we do not imply that households may intend not to comply with their intertemporal budget restriction (see Hammond, 1989, for the ensuing problems), although this may be of minor importance in a life-cycle model of labour supply with intertemporal separability.

The approach followed here nests the extreme assumptions of perfect perception of the marginal tax rate and of complete disregard. It rests on Rosen's (1976b) labour supply model with tax illusion which allows for differing effects (in absolute terms) of the gross wage and the tax rate on labour supply. We extend Rosen's work and focus on the determinants of tax illusion by introducing interaction effects of the $\log$ of one minus the tax rate with sociodemographic characteristics.

The outline of the paper is as follows. In Section II we briefly present the life-cycle model of quasi-linear preferences used in estimation, and describe the data in Section III. Estimation results are presented in Section IV, along with their implications for perceived retention rates. Section IV gives concluding comments. 
The motivation for our approach is based on the observation that structural empirical labour supply models usually either use the gross wage or the marginal wage rate as the price for leisure. Both approaches have in common that for a given information on (marginal) wages and hours (and sometimes additionally on expenditures), the position of the budget constraint is assumed to be known by the individual and the econometrician. Statistical inference on the preference structure is conditional on this information set. In the sequel we relax that assumption, and we define a misperception of the budget constraint as a situation where, for a given combination of hours supplied and marginal wage rate, the marginal rate of substitution between consumption and leisure does not coincide with the real marginal wage rate.

Figure 1

Perception and Misperception of the Marginal Tax Rate

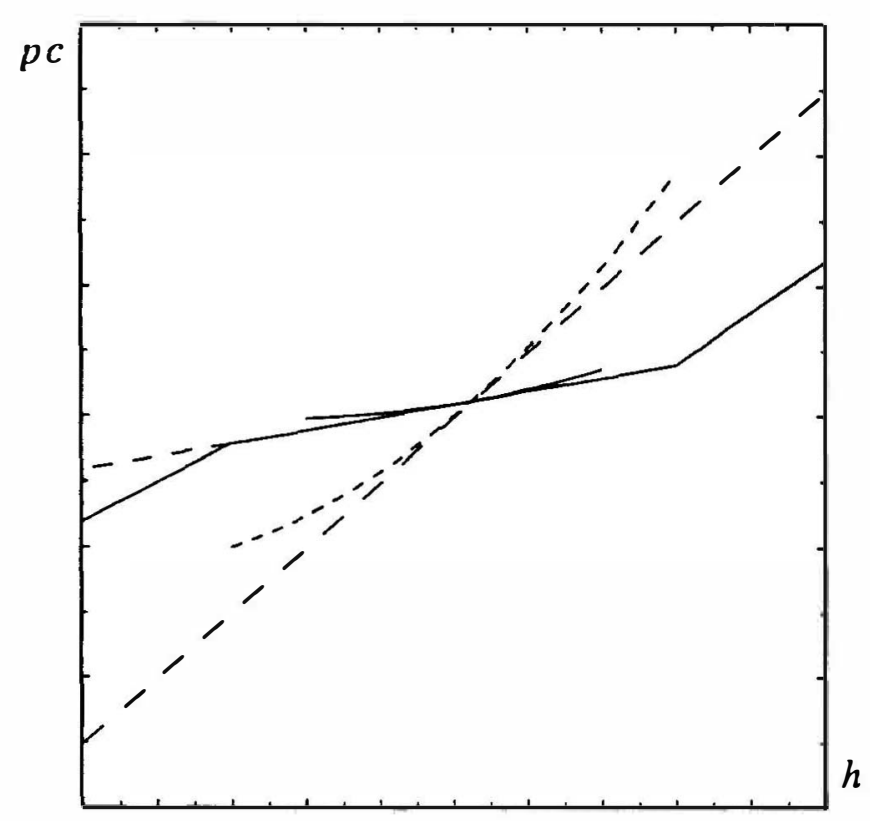


Figure I will help to understand what we have in mind when we combine a potential misperception of the budget constraint with the choice of a point that does not violate that constraint. The situation of a woman who takes her marginal tax rate into account is described by the solid lines. These are the true budget line and the indifference curve which is tangent to the budget line at the observed $(p c, h)$ point. The interrupted lines picture our representation of a misperception of the budget restriction. This cuts the true budget line at the observed $(p c, h)$ point but has the wrong slope there. Of course this representation is not completely internally consistent: it is difficult to see what mechanisms ensure $a$ posteriori the consistency of the 'mistaken' behaviour with the true budget restriction. Loosely speaking such mechanisms may be at work in the timing of the savings decisions and of the tax payment itself. But from the econometrician's point of view, this point is all that is observed. Then, wrongly assuming that an individual behaves according to the solid rather than the interrupted lines in Figure 1 (or vice versa), he will obtain biased estimates of her preference parameters.

In terms of our definition of perception of marginal taxes, the following empirical approach has three salient features: firstly, it relaxes the assumption that the true position and shape of the budget constraint is known to the individual; secondly, the perceived budget constraint is endogenous and depends on individual characteristics; thirdly it nests the two extreme cases of perfect knowledge and of complete ignorance.

An appealing and simple way to extend the neoclassical labour supply framework in the direction sketched above is to introduce interaction terms with the marginal tax rate. Given the situation in the German data, where consumption is not observed, an interesting starting point which is described in more detail by Laisney et al. (1993) is a life-cycle labour supply model based on additive intertemporal preferences where contemporaneous preferences are quasi-linear (indifference curves are parallel). This implies that there is no income effect on leisure, an apparently extreme assumption which however is not strongly rejected by the accumulated empirical evidence: many studies of female labour supply do indeed find insignificant income effects. Moreover, regardless of the normalization chosen for within-period preferences, hours supplied will be independent of assets in period 0 , interest rates and the rate of time preference. This is of course an extremely restrictive set of assumptions, but given the complexity of the estimation strategy pursued here, it will provide a convenient benchmark. In that case Frisch demands for leisure correspond exactly with Hicksian and with Marshallian demands and depend only on the real wage. Yet, since static models of female labour supply typically yield small income elasticities, this may not be such a bad model. In detail the period $t$ utility function is specified as 


$$
\mathrm{U}_{\mathrm{t}}\left(\mathrm{C}_{\mathrm{t}}, \mathrm{L}_{\mathrm{t}}\right)=\mathrm{F}_{\mathrm{t}}\left[\mathrm{C}_{\mathrm{t}}+\mathrm{V}_{\mathrm{t}}\left(\mathrm{L}_{\mathrm{t}}\right)\right]=: \mathrm{F}_{\mathrm{t}}\left[\mathrm{U}_{\mathrm{t}}^{*}\left(\mathrm{C}_{\mathrm{t}}, \mathrm{L}_{\mathrm{t}}\right)\right]
$$

for some increasing functions $F_{t}$ and $V_{t}$, where $C_{t}$ denotes household aggregate consumption in period $\mathrm{t}$, and $\mathrm{Lt}$ denotes the desired leisure of the female in period $t$. We specify the parsimonious parametric Box-Cox functional form $V_{t}\left(L_{t}\right)=\gamma t L_{t}\{\beta\}$, with $L^{\{\beta\}}:=\left(L^{\beta}-1\right) / \beta$ if $\beta \neq 0, \ln L$ otherwise. Utility increasing in leisure requires $\gamma_{t}>0$. This is easily achieved in estimation by specifying a logarithmic equation for this taste shifter. Convexity of indifference curves requires $\beta<1$. We use the following specification for the taste shifter and the gross wage

$$
\begin{gathered}
\ln \gamma_{t}=Z_{t} \phi+\varepsilon_{1 t}, \\
\ln W_{t}=X_{t} \psi+\varepsilon_{2 t},
\end{gathered}
$$

with bivariate normality for the error terms. With the condition that a woman chooses hours equating her marginal rate of substitution and her perceived net wage, this results in the following form for an interior solution in desired leisure:

$$
\mathrm{Z} \phi+\varepsilon_{1}=-(\beta-1) \ln (\overline{\mathrm{L}}-\mathrm{N})+\ln \mathrm{W}+\alpha \ln [1-\tau(\mathrm{Y}, \mathrm{WN})],
$$

where $\overline{\mathrm{L}}$ denotes the amount of time available for allocation between market time and 'leisure', $\mathbf{N}$ are the desired hours of work of the individual, $\mathrm{Y}$ is her husband's income, exogenous, and $\mathrm{W}$ is her gross wage rate. $\tau$ denotes the marginal tax rate, which is in Germany a function of the individual's earnings and of the other income of the household, here her husband's income. $\alpha$ denotes an essential household-specific multiplier for this study: its presence corresponds to taking account of a 'subjective' marginal retention rate $\rho$ * defined by

$$
\rho^{*}=(1-\tau)^{\alpha}
$$

In the following the perception rate $\alpha$ depends on a vector of socio-economic characteristics $\mathrm{V}$ that should be correlated with the individual's knowledge of the tax system. Assuming linearity we have $\alpha=\mathrm{V} v$ where $v$ is a parameter vector to be estimated. For $\alpha=1$ condition (4) reflects the equilibrium condition (for an interior solution) under perfect knowledge about marginal wage rates. Given $\alpha=0$ we are in the framework where marginal tax rates are completely 
ignored. However, in this approach we do not restrict $\alpha$ to lie between 0 and 1 . Thus a negative $\alpha$ would lead to a retention rate above one and $\alpha>1$ would indicate an 'exaggeration' of marginal tax rates.

Of course, identification of the perception rate $\alpha$ hinges both on functional form and on exclusion restrictions. In the same way that it is difficult to disentangle the effects of children on preferences from their effect on the amount of time available for allocation between work and leisure (see Nakamura and Nakamura 1992), we will clearly face identification problems. However, approaches ignoring the perception issue are even more subject to this critique, and this study must be seen as a first step in this direction.

Our econometric treatment of observations with missing wage information, or with irregular employment or unemployment takes care of some of the problems that availability of detailed information on demand conditions might help to handle more explicitly. Actual hours, but also the desired hours available in our data, are influenced by the availability of the corresponding (hours, wage) offers. Most respondents turn out to report desired hours that are multiples of 5 . We shall cope with this by considering ranges of desired hours as the observed dependent variable rather than the actual level of desired hours. This technique is used by Blundell et al. (1993) but we are in a better position to use it here, because we do not have to make their assumption that actual and desired hours fall into the same interval.

\section{DATA}

We use the unbalanced sample from Laisney et al. (1993). The selection is summarized in Table 1 . In order to avoid the non-convexity of the budget set caused by means-tested benefits, we restricted the sample used in the estimation to females who would not be entitled to the means-tested benefits giving rise to a marginal tax rate of $100 \%$ at zero hours. This selection rule only depends on the 'unearned income' and on the demographics of the household, and is thus exogenous in the framework of our assumptions. We refer the reader to Laisney et al. (1993) for the description of the variables used in the determination of the form of the budget set of each household, since this represents a large portion of that paper. Gross wages for the participants have been computed as reported gross monthly earnings of the last month divided by reported average working hours (per week) of the last month, multiplied by 4.3 . The resulting number is multiplied by $13 / 12$ in order to account for the additional income component corresponding to the 'thirteenth month' practice. In our final sample we consider observations in the lower and the upper percentile of the wage 
distribution as indicating implausible values for either the working hours or the gross monthly income. Moreover, we discard the information on wages for several particular groups of observations and treat them like the job seekers, for whom the only information we use is the fact that their desired hours are positive.

Table I

Sample Selection and Sample Sizes

\begin{tabular}{llllll}
\hline Sequential Selection Criteria & 1985 & 1986 & 1987 & 1988 & 1989 \\
\hline all females with valid interview & 5631 & 5378 & 5308 & 5068 & 4930 \\
German nationality & 4287 & 4090 & 4010 & 3774 & 3586 \\
age 25-57 & 2434 & 2328 & 2262 & 2129 & 2038 \\
married and living together with partner & 1903 & 1781 & 1736 & 1633 & 1555 \\
no partner change, marriage, divorce, etc.* & 1846 & 1726 & 1669 & 1582 & 1510 \\
head or wife of head of household & 1842 & 1717 & 1656 & 1575 & 1499 \\
no other adults in household & 1842 & 1717 & 1656 & 1574 & 1499 \\
not self-employed & 1734 & 1621 & 1548 & 1477 & 1411 \\
af ter deleting missing values** & 1530 & 1419 & 1361 & 1266 & 1192 \\
no benefits at zero hours & 1328 & 1237 & 1193 & 1139 & 1068 \\
\hline * in last 18 months & & & & & \\
** except hours and female income information & & & & & \\
\hline
\end{tabular}

The variables used in estimation may be summarily described as follows (see Table 2 for some descriptive statistics): wages are real gross wages; hours are desired hours for the participants, defined as normal weekly hours over the year; non-participants report being registered as unemployed, or being out of the labour force and, in case they answered yes to the question 'future participation (yes, perhaps, no)', declared that they did not look for a job that would begin immediately; seekers report being registered as unemployed, or being out of the labour force and, in case they answered yes to the question 'future participation (yes, perhaps, no)' declared that they did look for a job that would begin 


\section{Table 2}

Descriptive statistics

\begin{tabular}{|c|c|c|c|c|c|c|c|c|c|c|}
\hline $\begin{array}{l}\text { Year } \\
\text { Variable }\end{array}$ & $\begin{array}{l}1985 \\
\text { mean }\end{array}$ & std & $\begin{array}{l}1986 \\
\text { mean }\end{array}$ & std & $\begin{array}{l}1987 \\
\text { mean }\end{array}$ & std & $\begin{array}{l}1988 \\
\text { mean }\end{array}$ & std & $\begin{array}{l}1989 \\
\text { mean }\end{array}$ & std \\
\hline price index & 1 & 0 & 0.998 & 0 & 0.999 & 0 & 1.01 & 0 & 1.039 & 0 \\
\hline non-participants & 0.49 & & 0.49 & & 0.48 & & 0.48 & & 0.47 & \\
\hline seekers & 0.03 & & 0.04 & & 0.04 & & 0.02 & & 0.04 & \\
\hline participants & 0.48 & & 0.46 & & 0.47 & & 0.49 & & 0.50 & \\
\hline $\begin{array}{l}\text { participants without } \\
\text { wage information }\end{array}$ & 0.13 & & 0.13 & & 0.11 & & 0.11 & & 0.13 & \\
\hline $\begin{array}{l}\text { real hourly wage } \\
\text { (DM 1985)** }\end{array}$ & 14.9 & 5.41 & 16.0 & 7.67 & 16.1 & 6.3 & 17.0 & 7.05 & 17.0 & 7.00 \\
\hline $\begin{array}{l}\text { desired woekly } \\
\text { hours* }\end{array}$ & 25.4 & 9.64 & 26.1 & 8.73 & 26.9 & 9.10 & 25.5 & 8.85 & 26.5 & 8.91 \\
\hline $\begin{array}{l}\text { actual weekly } \\
\text { hours* }\end{array}$ & 30.4 & 11.2 & 32.0 & 11.2 & 30.2 & 11.3 & 29.4 & 11.7 & 29.9 & 10.8 \\
\hline age & 41.1 & 9.01 & 41.5 & 8.99 & 41.5 & 8.90 & 41.5 & 8.91 & 41.4 & 8.94 \\
\hline potential experience & 25.8 & 9.32 & 26.5 & 9.15 & 26.7 & 8.78 & 27.1 & 9.00 & 27.3 & 8.06 \\
\hline Realschule & 0.22 & & 0.21 & & 0.21 & & 0.21 & & 0.21 & \\
\hline $\begin{array}{l}\text { Fachoberschule, } \\
\text { Abitur }\end{array}$ & 0.08 & & 0.08 & & 0.08 & & 0.07 & & 0.07 & \\
\hline $\begin{array}{l}\text { youngest child } \\
0-2 \text { years }\end{array}$ & 0.10 & & 0.11 & & 0.10 & & 0.09 & & 0.07 & \\
\hline $3-5$ & 0.12 & & 0.11 & & 0.12 & & 0.13 & & 0.14 & \\
\hline $6-11$ & 0.16 & & 0.16 & & 0.16 & & 0.17 & & 0.18 & \\
\hline $12-15$ & 0.15 & & 0.14 & & 0.12 & & 0.10 & & 0.09 & \\
\hline $\begin{array}{l}\text { number of children } \\
0-5\end{array}$ & 0.27 & 0.55 & 0.29 & 0.59 & 0.27 & 0.55 & 0.27 & 0.55 & 0.24 & 0.51 \\
\hline $6-11$ & 0.30 & 0.56 & 0.31 & 0.58 & 0.33 & 0.62 & 0.35 & 0.63 & 0.36 & 0.64 \\
\hline $12-15$ & 0.26 & 0.50 & 0.23 & 0.48 & 0.21 & 0.46 & 0.20 & 0.45 & 0.19 & 0.43 \\
\hline $16-25$ & 0.58 & 0.84 & 0.57 & 0.82 & 0.58 & 0.82 & 0.58 & 0.83 & 0.60 & 0.81 \\
\hline less than $20^{\prime}$ inhabit. & 0.30 & & 0.29 & & 0.29 & & 0.29 & & 0.29 & \\
\hline $\begin{array}{l}\text { marginal tax rate } \\
\text { at zero hours }\end{array}$ & 0.15 & 0.07 & 0.15 & 0.07 & 0.15 & 0.07 & 0.16 & 0.07 & 0.16 & 0.07 \\
\hline $\begin{array}{l}\text { marginal tax rate } \\
\text { at desired hours }\end{array}$ & 0.29 & 0.19 & 0.29 & 0.18 & 0.30 & 0.18 & 0.29 & 0.17 & 0.30 & 0.17 \\
\hline $\begin{array}{l}\text { benefits at } \\
\text { zero hours }\end{array}$ & 0.13 & & 0.11 & & 0.13 & & 0.11 & & 0.10 & \\
\hline
\end{tabular}

* participants with 'accepted' wage rates only

N.B.: variables for which no entry appears in the column headed 'std' (standard deviation) are dummy variables. 
immediately; participants report working full- or part-time, or being in vocational training, or working irregularly, or report positive desired hours or positive observed hours; participants with missing wage information have missing information on earnings or on observed hours or on desired hours, or work irregularly, or report to work full-time but with average weekly hours below 20, or report to work part-time but with average weekly hours above 35 , or their computed gross nominal wage is in the upper or lower $5 \%$ of the distribution (we thus have four categories of observations: non-participants, seekers, participants with missing information, and participants with complete information); schooling is described by three dummies for the highest grade in general education (with the corresponding years of schooling in brackets) 'Hauptschule' (9) 'Mittlere Reife' (10) 'Abitur' or 'Zulassung zur Fachhochschule' (13 and 12, respectively); potential experience is (Age - Years of schooling - 6) / 10; for children there are two groups of variables: (i) numbers of children in the categories up to 5 years of age, between 6 and 11 , between 12 and 15, older than 15 and still in education; (ii) dummies youngest child up to 2 years of age, between 3 and 5, between 6 and 11 , between 12 and 15, older than 15 and still in education; urbanization grade (Boustedt) the retained dummy covers the categories town, village, rural (below 20' inhabitants).

\section{RESULTS}

Due to a substantial clustering of hours we restrict our attention to a model specification where hours information is grouped according to the cut-points $22.5,27.5,32.5,37.5$ hours per week. The choice of these cut-points is justified in Laisney et al. (1993). We estimate the model for all five cross-sections by maximum likelihood and use the minimum distance estimation technique to enforce the panel structure on the cross-section estimates under the assumption that individual effects ar not correlated with the regressors (see Chamberlain 1984). In Table 3 we present our preferred estimates, based on the choice of $L=10.5$ hours a day for the amount of time available for allocation between market time and leisure. In opposition with most of the literature on this point, we find that this choice does matter. Ideally, one would want to allow $\bar{L}$ to vary with demographics, but this would strain identification one step further than we already reluctantly do. The value of 10.5 corresponds approximately to an estimate obtained by restricting the perception rate $\alpha$ to be equal to 1 .

A first feature of the results is that the estimate of the wage elasticity of leisure is high in absolute terms compared to the results of previous studies using the same data (Laisney et al. 1993, and Hujer and Schnabel 1994). The parameters 
of the wage equation and the taste shifter are fairly standard. The (log-) wage profile is bell-shaped in terms of potential experience, with a maximum at 22 years of experience. In interpreting the coefficients in the taste shifter, it must be remembered that a positive impact on the taste shifter increases the weight of leisure in the utility function. Having children in any of the defined age groups implies a reduction of hours supplied, as expected.

Most interesting for the present study are the results obtained for the coefficients appearing in the perception rate. Positive coefficients on the different child dummies in $V$ (these are jointly significant, although the individual coefficients are not) indicate that women with children are likely to have a better perception of the marginal tax rate than other women do. We offer the following tentative explanations for this finding. If families with children find it more difficult than childless couples to make ends meet, they may be more inclined to take into account their true marginal tax rate. Moreover, having access to special tax allowances for families with children may produce a better knowledge about the true tax rate. However, the latter argument is not supported by our finding that owning a house, and thus possibly receiving corresponding tax reductions, has no significant impact on the perception rate. The clearest finding is that the neoclassical assumption that individuals are perfectly aware of the implications of marginal tax rates appears more likely to hold for women with a higher educational degree than for the reference group (Hauptschule). This is perhaps not surprising a posteriori, but we did not expect education to stand out as the main determinant: we would have expected age to play some role, although this is obviously partly captured by the child dummies.

Table 4 gives descriptive statistics on the distribution of the predicted individual perception rates, computed for every year and individual. The mean of 0.23 is far from Rosen's (1976b) estimate for a constant $\alpha$ close to unity. For $70 \%$ of the individuals in the sample the predicted $\alpha$ lies between 0 and 1 with a median value of 0.15 . The table also presents individual t-statistics (computed on the basis of the estimated parameters and the individual values of the variables entering $\alpha$ ) which allow various one-sided and two-sided tests. Thus $\alpha$ is significantly negative for only about $1 \%$ of the sample. In terms of our model these are people who overstate redistribution in their favour. For more than half of the sample we cannot reject the assumption of total disregard of the marginal tax rate at the $5 \%$ level ( $\alpha=0$ against $\alpha \neq 0$ ), whereas it is only for a little more than 10 per cent of the individuals that we are unable to reject the hypothesis of exact perception ( $\alpha=1$ against $\alpha \neq 1$ ). For no individual is $\alpha$ significantly above 1 . This means that, contrary to what Wahlund (1987) reports for Sweden, we do not find in our German sample any marked tendency to exaggerate the marginal tax rate. 


\section{Table 3}

Estimates for the Coefficients of Equations (3) and (4):

(Minimum Distance Estimation, Intercepts and Covariance Structure Unrestricted)

\begin{tabular}{|c|c|c|c|}
\hline & & coef. & t-value \\
\hline$\beta$ & & 0.715 & 11.6 \\
\hline Wage equation $(\psi)$ & $\begin{array}{l}\text { intercept } 1985 \\
1986 \\
1987 \\
1988 \\
1989 \\
\text { potential experience } / 10 \\
\text { pot. experience squared } / 1000 \\
\text { less than 20' inhabitants } \\
\text { Realschule } \\
\text { Fachoberschule, Abitur }\end{array}$ & $\begin{array}{r}2.495 \\
2.560 \\
2.600 \\
2.624 \\
2.647 \\
0.171 \\
-0.515 \\
0.011 \\
0.154 \\
0.281\end{array}$ & $\begin{array}{r}34.0 \\
34.9 \\
34.4 \\
33.8 \\
33.8 \\
3.1 \\
.4 .9 \\
0.6 \\
6.0 \\
6.0\end{array}$ \\
\hline Taste shifter $(\phi)$ & $\begin{array}{cc}\text { intercept } 1985 & \\
1986 & \\
1987 & \\
1988 & \\
1989 & \\
\text { number of children } & 0-5 \\
& 6-11 \\
& 12-15 \\
& 16-25\end{array}$ & $\begin{array}{l}4.654 \\
4.729 \\
4.775 \\
4.782 \\
4.842 \\
0.246 \\
0.135 \\
0.080 \\
0.049\end{array}$ & $\begin{array}{r}9.9 \\
10.0 \\
10.2 \\
10.2 \\
10.3 \\
6.0 \\
5.1 \\
2.7 \\
2.4\end{array}$ \\
\hline Perception (v) & $\begin{aligned} & \text { intercept } 1985 \\
& 1986 \\
& 1987 \\
& 1988 \\
& 1989 \\
& \\
& \text { youngest child } 0-2 \text { years } \\
& 3-5 \\
& 6-11 \\
& 12-15 \\
& \text { Realschule } \\
& \text { Fachoberschule, Abitur }\end{aligned}$ & $\begin{array}{r}0.043 \\
0.002 \\
-0.095 \\
-0.010 \\
-0.170 \\
0.184 \\
-0.008 \\
0.131 \\
0.074 \\
0.225 \\
0.352\end{array}$ & $\begin{array}{r}0.6 \\
0.0 \\
-1.3 \\
-0.1 \\
-1.6 \\
1.9 \\
-0.1 \\
1.9 \\
1.0 \\
4.4 \\
4.1\end{array}$ \\
\hline Covariance structure & $\begin{array}{r}\sigma 1985 \\
1986 \\
1987 \\
1988 \\
1989\end{array}$ & $\begin{array}{l}0.430 \\
0.456 \\
0.416 \\
0.415 \\
0.351\end{array}$ & $\begin{array}{l}0.052 * \\
0.045 \\
0.057 \\
0.055 \\
0.059\end{array}$ \\
\hline & $\begin{array}{r}\rho 1985 \\
1986 \\
1987 \\
1988 \\
1989\end{array}$ & $\begin{array}{l}0.737 \\
0.828 \\
0.798 \\
0.817 \\
0.777\end{array}$ & $\begin{array}{l}0.066 \\
0.051 \\
0.060 \\
0.060 \\
0.065\end{array}$ \\
\hline & $\begin{array}{r}\sigma_{2} 1985 \\
1986 \\
1987 \\
1988 \\
1989 \\
\end{array}$ & $\begin{array}{l}0.341 \\
0.375 \\
0.366 \\
0.380 \\
0.368 \\
\end{array}$ & $\begin{array}{l}0.013 \\
0.019 \\
0.015 \\
0.016 \\
0.016 \\
\end{array}$ \\
\hline
\end{tabular}


Distribution of Estimated Perception Rates (First Line) and of t-Statistics for the Test of the Special Cases of Interest (Second and Third Lines), Pooled 1985-1989

\begin{tabular}{lrrrrrr}
\hline & \multicolumn{5}{c}{ Quantile } & Mean \\
& $1 \%$ & $25 \%$ & $50 \%$ & $75 \%$ & $99 \%$ & \\
\hline$\alpha_{i}=V_{i} v$ & -0.20 & -0.04 & 0.15 & 0.44 & 1.11 & 0.23 \\
$H_{0}: \alpha_{i}=0$ (complete disregard) & -1.67 & -0.34 & 1.10 & 2.97 & 5.51 & 1.38 \\
$\mathrm{H}_{0}: \alpha_{i}=1$ (exact perception) & -10.16 & -7.37 & -5.87 & -3.78 & 0.50 & -5.60 \\
\hline
\end{tabular}

Another interesting empirical question is whether the perception is related to the magnitude of the marginal tax rate and to the labour market status of the individual. The plots of the perception rate $\alpha$ against the marginal tax rate according to labour market status, given in Figures $2 a$ and $2 b$ indicate on the whole an increasing relationship (the irregularities around marginal tax rates of 0.3 to 0.4 or in excess of 0.65 are caused by very few individuals, as documented in Figure 3b). The plots show kernel regressions of $\alpha$ on $\tau$ with confidence bands constructed with \pm twice the standard deviation of the conditional mean. Individuals with a marginal tax rate around 0.35 and individuals with extremely high marginal tax rates are most likely to take their tax rates into account when they make their labour supply decisions. However, even for these two small groups $\alpha$ is far from being unity. Comparing across groups, we find that the perception of part-time workers seems more accurate than that of full-time workers, which is consistent with the higher education, on average, of part-time workers, and that seekers have a flatter profile than non-participants. This is consistent with lower reservation wages for seekers than for non-participants.

For individuals with zero marginal tax rate, whatever their labour market position, the perception of the marginal tax rate is irrelevant for their labour supply decision, since at a tax rate of zero the impact of misperception on hours supplied is nil in our model. Therefore it is interesting to look at the relationship between the actual marginal tax rate $\tau$ and the perceived marginal tax rate $\tau$, where the latter is defined by the relation $(1-\tau)^{\alpha}=1-\tau^{*}$, and represents the tax rate that would produce the same behaviour if exactly perceived. This relationship is depicted in Figures $3 a$ and $3 b$, where on top of the kernel plots we have also represented each individual point $\left(\tau, \tau^{*}\right)$. The clustering of values 
of $\tau$ around some of the lower values correspond to tax allowances and to an allowance for the payment of social contributions (see Laisney et al. 1993, for details). The solid straight line shows equality between $\tau$ and $\tau^{*}$, or exact perception. One way to look at the pictures is to ask what the perceived marginal tax rate is on average for a given marginal tax rate of, say 0.45 . That value is 0.18 for non-participants, 0.14 for seekers, 0.08 for part-timers and 0.06 for full-timers. It is small, but the relative magnitudes are in intuitive accordance with the observed labour market status. It is worth noting however that a possible explanation for this ranking could lie in the fact that our model takes no account of the 'investment in human capital' aspect of market work.

\section{CONCLUSIONS}

This paper is concerned with the empirical issue of whether married women have an exact perception of their marginal tax rate when making their labour supply decisions, and with the characterization of differences in perception across socio-economic groups. The approach adopted differs from standard neoclassical labour supply approaches only by the choice of the functional form: i.e., the deviation from exact perception is only identified by assuming a specific form for the underlying labour supply functions. Hence the statistical significance of the parameters that reflect this departure might well be the result of a misspecification of the labour supply function, rather than evidence against exact perception. Given this qualification, and contrary to the findings of Rosen (1976b), who does not find a significant departure from a correct perception of marginal taxes, our results do not support the neoclassical view of an exact perception for more than $10 \%$ of the sample used, whereas complete disregard of the marginal tax rate concerns only $5 \%$ of the sample and may well be fully justified by negligible marginal rates for those individuals. The important finding is thus that for most individuals in the sample the perception of the marginal tax rate is not exact, although it may well be optimal in some sense if the cost of information is taken into account. The other important finding of the paper is that perception increases with education and is also higher (but less significantly) for women with children.

It is clear that the assumptions adopted here deserve questioning in several respects. A promising extension of the labour supply model within the neoclassical tradition would be to jointly explain labour supply and learning behaviour about taxes. In order to disentangle the effects of learning behaviour on labour supply a longer panel than the one used here is likely to be necessary, though. Moreover, our approach to modelling the individual's tax perception 
remains fairly traditional in the sense that perception is explained by standard variables used in labour supply specifications. Another path of future research could incorporate insights from economic psychology. If tax perception is regarded as the mediation between tax stimulus and labour supply response to that stimulus, one should incorporate 'soft' variables such as the beliefs about the disincentive effects of taxation, or perceptions of the purpose of taxation and preferences about the redistribution of wealth (see, for instance Lewis 1982, and Levine 1993). Such an approach, however, suffers from the lack of interpretability of the coefficients in terms of a structural model.

Finally, in order to assess the overall impact of taxes on labour supply, a closer look should be taken at the qualitative dimensions of labour supply (motivation, job satisfaction etc...) rather than at the participation and hours decisions alone. An approach along these lines would be suitable to analyze the effects of tax changes on labour supply and tax evasion. 
Figure $2 a$

Kernel Regression of Estimated Individual Perception Rate $\alpha_{i}$ on Marginal Tax Rate $\tau_{i}$ for Non-Participants (top) and Seekers (bottom)
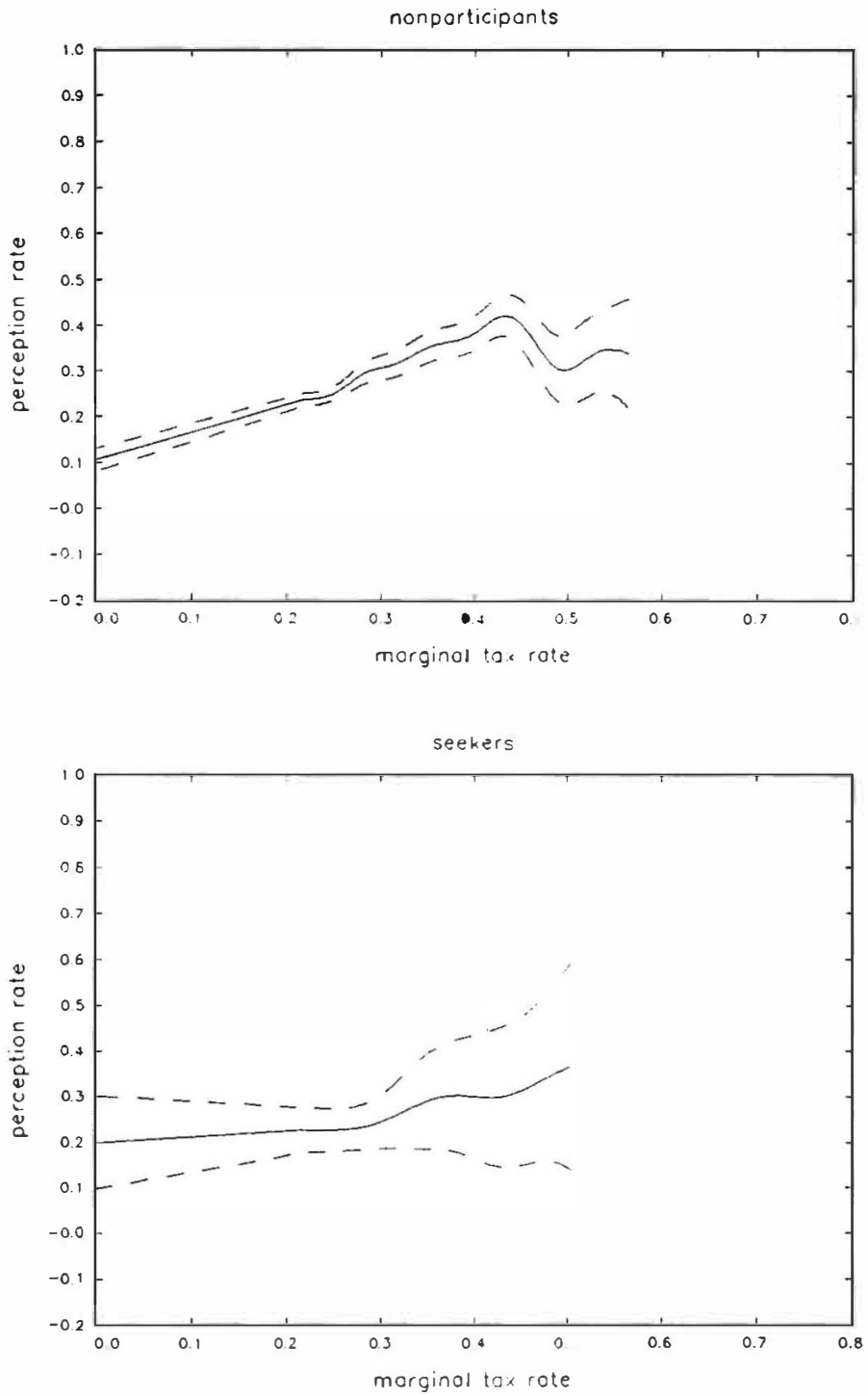


\section{Figure $2 b$}

Kernel Regression of Estimated Individual Perception Rate $\alpha_{i}$ on Marginal Tax Rate $\tau_{i}$ PartTime Workers (top) and Full-Time Workers (bottom)
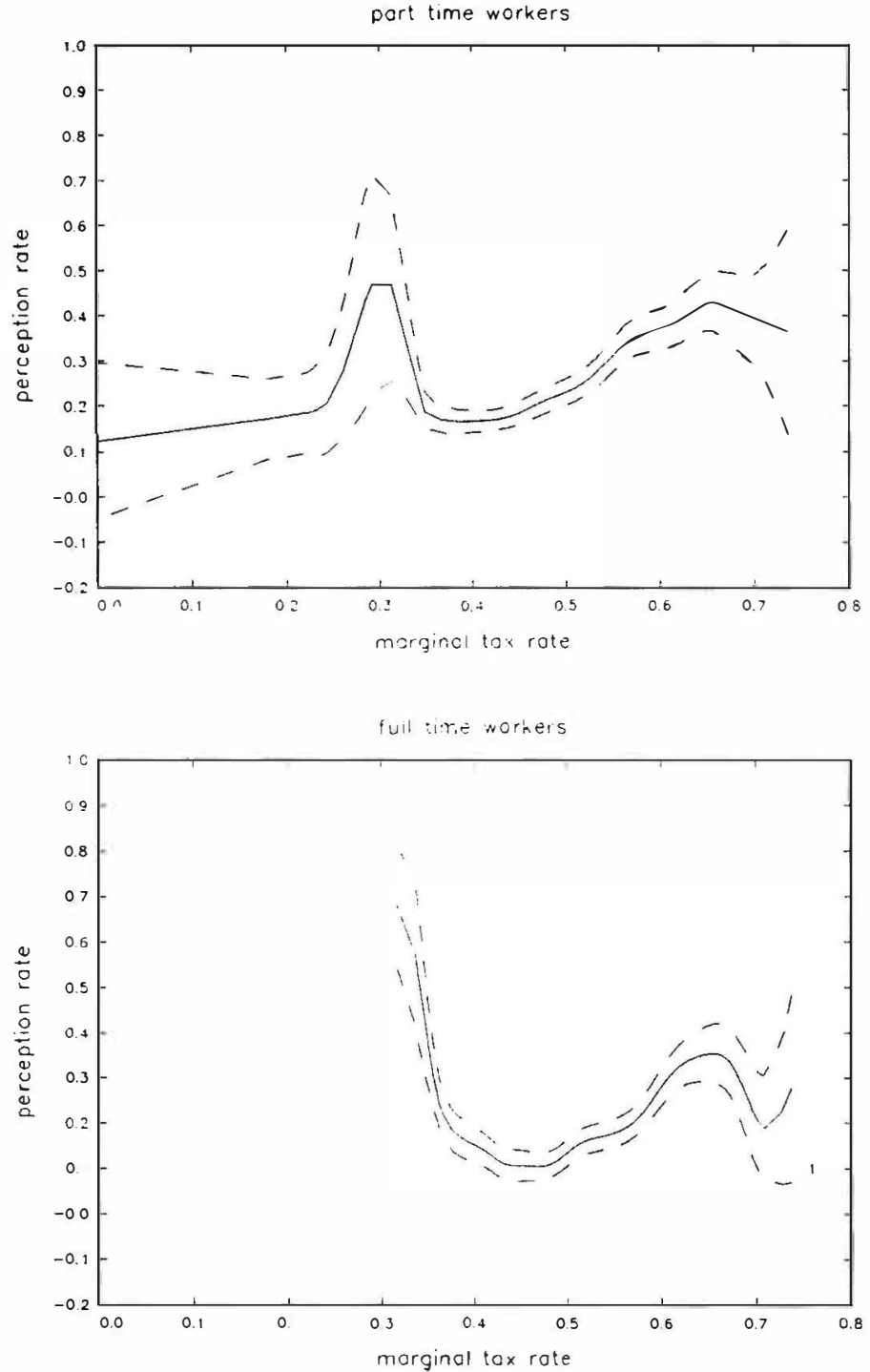
Figure $3 a$

Kernel Regression of Estimated Perceived Marginal Tax Rate $\dot{\tau}_{i}$ on Marginal Tax Rate $\tau_{i}$ for Non-Participants (top) and Seekers (bottom)
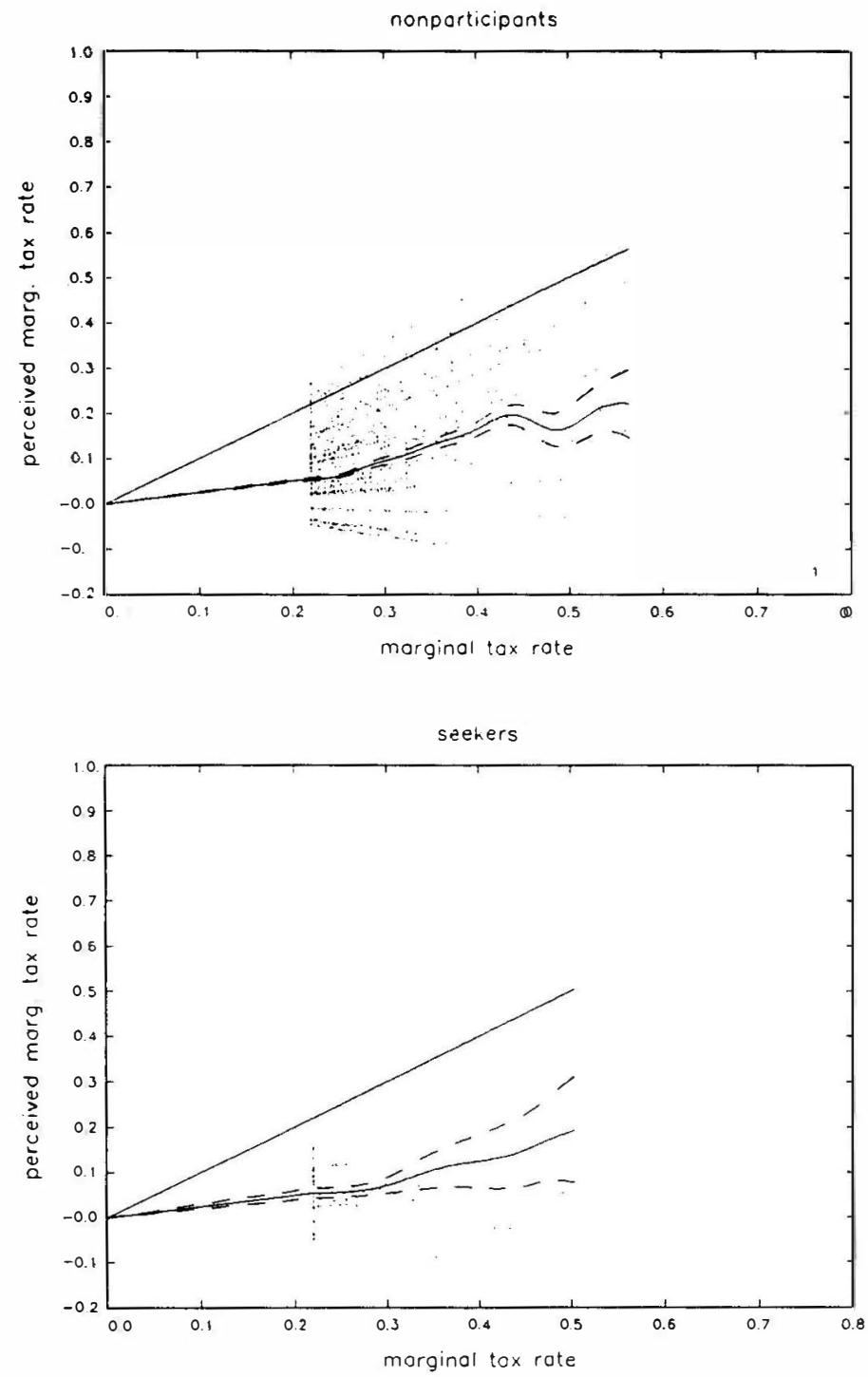


\section{Figure $3 b$}

Kemel Regression of Estimated Perceived Marginal Tax Rate $\tau_{i}^{*}$ on Marginal Tax Rate $\tau_{i}$ PartTime Workers (top) and Full-Time Workers (bottom)

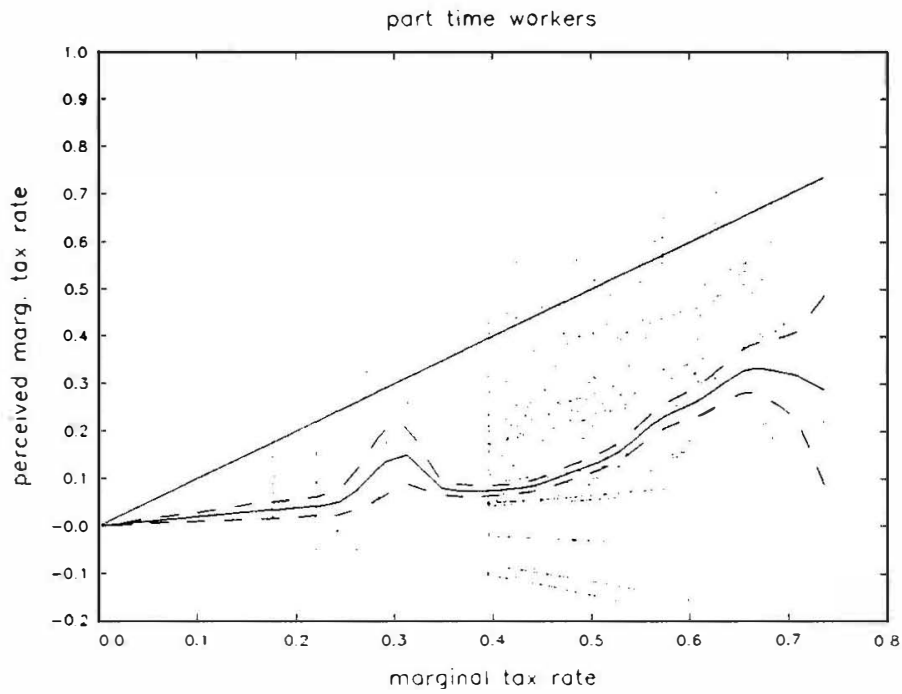

full tine workers

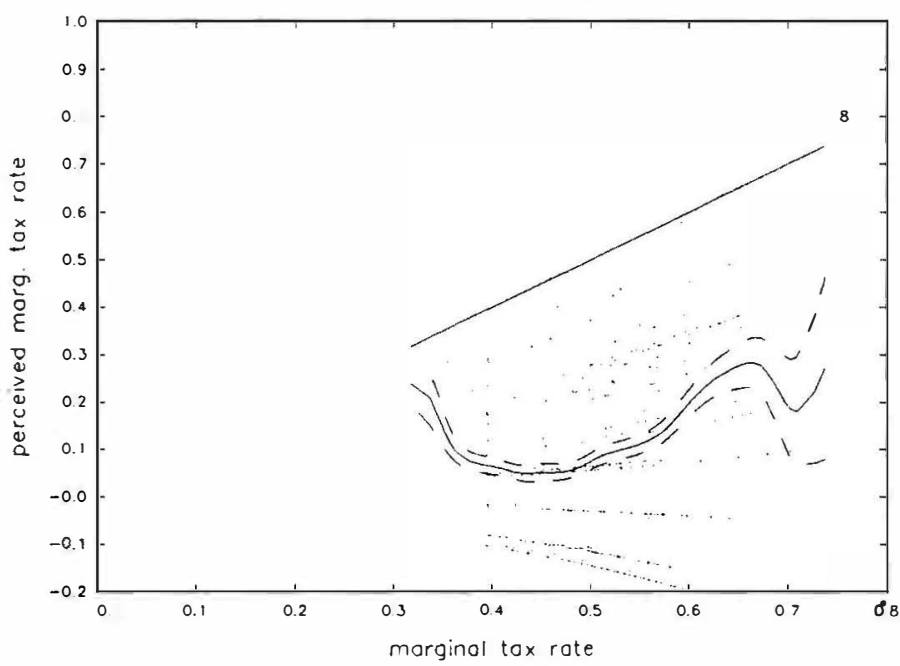


Atkinson, Anthony B. and Joseph E. Stiglitz (1980). Lectures in Public Economics. Maidenhead: McGraw-Hill.

Blundell, Richard W., Francois Laisney and Michael Lechner (1993). Alternative Interpretations of Hours Information in an Econometric Model of Labour Supply, Empirical Economics. 18: 543-556.

Chamberlain, Gary (1984). Panel Data, Ch. 22 in: Zvi Griliches and Michael D. Intriligator (eds.), Handbook of Econometrics., Vol II. North-Holland, Amsterdam.

Dilnot, Andrew and Alan Duncan (1992). Thinking about Labour Supply, Journal of Economic Psychology. 13: 687-713.

Hammond, Peter (1989). On the Impossibility of Perfect Capital Markets, EUI Working Papers in Economics No. 90/5.

Hausman, Jerry A. (1985). The Econometrics of Nonlinear Budget Sets, Econometrica. 53: 1255-1282.

Hujer, Reinhard and Reinhold Schnabel (1994). The Impact of Regional and Sectoral Labor Market Conditions on Wages and Labor Supply: An Empirical Analysis for Married Women Using West-German Panel Data, Empirical Economics. 19: 19-35.

Kahneman, D. and A. Tversky (1979). Prospect Theory: An Analysis of Decisions under Risk, Econometrica. 47: 263-491.

König, Heinz, Francois Laisney, Michael Lechner and Winf ried Pohlmeier (1993). On the Perception of Marginal Tax Rates: Evidence from French and German Data on Married Women, ZEW Discussion Paper. 93-109.

Laisney, François, Michael Lechner, Arthur Van Soest and Gerhard Wagenhals (1993). A Life Cycle Labour Supply Model with Taxes Estimated on German Panel Data: The Case of Parallel Preferences, The Economic and Social Review. 24: 335-368.

Levine, David I. (1993). The Effects of Non-Traditional Attitudes on Married Women's Labor Supply, Journal of Economic Psychology. 14: 665-679.

Lewis, A. (1982). The Psychology of Taxation. Oxford: Martin Robertson.

Moffitt, Robert (1983). The Economics of Welfare Stigma, American Economic Review. 73: 55-62.

Nakamura, Alice and Masanao Nakamura (1981). A Comparison of the Labor Force Behavior of Married Women in the United States and Canada, with Special Attention to the Impact of Income Taxes, Econometrica. 49: 451-489.

Nakamura, Alice and Masanao Nakamura (1992). The Econometrics of Female Labor Supply and Children, Econometric Reviews. 11: 1-71.

Pommerehne, Wemer W. and Friedrich F. Schneider (1978). Fiscal Illusion, Political Institutions, and Local Public Spending, Kyklos. 31: 381-408.

Rosen, H.S. (1976a). Taxes in a Labor Supply Model with Joint Wage-Hours Determination, Econometrica. 44: 485-507.

Rosen, H.S. (1976b). Tax Illusion and the Labor Supply Model of Married Women, Review of Economics and Statistics. 58: 167-180.

Wahlund, Richard (1987). Does Lowering the Marginal Tax Rates Matter? paper presented at the 12th Annual Colloquium of the IAREP, the International Association for Research on Economic Psychology, Århus, September 25-28.

Wahlund, Richard (1992). Tax changes and economic behaviour: The case of tax Evasion. Journal of Economic Psychology. 13: 657-677. 
In the face of complex budget constraints the assumption that individuals act on the basis of complete knowledge of the tax system is a theoretical borderline. The specific issues examined in this empirical study are (i) to what extent do consumers (here married women) perceive their true marginal tax rate when they make their labour supply decisions, and (ii) how does the perception of the marginal tax rate differ among various socio-economic groups? Using German panel data we find that, against conventional wisdom, the assumption of complete knowledge of the tax system does not fit the data well, and that education appears to be the main determinant of a correct perception of the marginal tax rate.

\section{ZUSAMMENFASSUNG}

Angesichts der ïblichen Komplexität der Budgetmengen ist die Annahme, dass Individuen ihre Entscheidungen unter vollständiger Kenntnis des Steuersystems treffen, nur ein theoretischer Grenzfall. Die spezifischen Fragestellungen dieser empirischen Studie sind folgende: (i) inwiefern basieren die Arbeitsangebotsentscheidungen verheirateter Frauen auf einer exakten Kenntnis des Grenzsteuersatzes, und (ii) wie variiert die Perzeption dieses Grenzsteuersatzes in verschiedenen sozioökonomischen Gruppen? Unsere Ergebnisse anhand des SOEPs zeigen, dass entgegen der in der Arbeitsangebotsliteratur vorherrschenden Meinung, die Annahme einerexakten Perzeption mit den Daten nicht zu vereinbaren ist und dass die Schulausbildung eine Hauptdeterninante einer korrekten Perzeption des Grenzsteuersatzes darstellt.

\section{RÉSUMÉ}

Face à la complexité des contraintes budgétaires, l'hypothèse que les indi vidus agissent en pleine connaissance du système fiscal apparaît comme un cas limite théorique. Les questions spécifiques auxquelles cette étude empirique tente d'apporter une réponse sont (i) dans quelle mesure les agents (ici des femmes mariées) basent-ils leurs décisions d'offre de travail sur une connaissance exacte de leur taux marginal d'imposition, et (ii) comment la peception de ce taux marginal varie-t'elle entre groupes socio-économiques? Nos résultats, obtenus à l'aide de données de panel pour l'Allemagne, montrent que, contrairement à l'opinion répandue dans la littérature sur l'offre de travail, l'hypothèse d'une connaissance exacte du système fiscal ne s'accorde pas bien aux données, et que l'éducation (formation initiale) apparaît comme le déterminant principal d'une perception correcte du taux marginal d'imposition. 